\title{
Strengthening the conservation value of ex situ tree collections
}

\author{
Nicole Cavender, Murphy Westhood, Catherine Bechtoldt \\ Gerard Donnelly, Sara Oldfield, Martin Gardner \\ David Rae and William McNamara
}

\begin{abstract}
With $10 \%$ of trees ( $>8,000$ species) threatened with extinction there is an urgent need for botanical gardens to protect threatened trees in dedicated conservation collections. Species conservation is mentioned in the mission statements of most major botanical gardens, yet the actual conservation value of existing ex situ tree collections is low. We conducted interviews with members of the botanical garden community and organized a symposium at the 5th Global Botanic Gardens Congress to identify challenges and collect recommendations to improve living ex situ tree collections. We summarize and evaluate this information to facilitate gardens becoming more effective agents for global tree conservation. Experts agree that gardens offer valuable strengths and assets for tree conservation. Some challenges exist, however, including a lack of strategic conservation focus, collection management limitations, gaps in fundamental biological information for trees, and a lack of global coordination. Solutions are offered to facilitate gardens and arboreta of all sizes to participate more effectively in tree conservation. Prioritizing genetically diverse tree collections, participating in conservation networks, developing tree-specific conservation models and guidelines, and strengthening tree science research efforts are a few examples. Most importantly, a more coordinated global effort is needed to fill knowledge gaps, share information, and build conservation capacity in biodiversity hotspots to prevent the loss of tree species.
\end{abstract}

Keywords Arboretum, botanical garden, ex situ, Global Strategy for Plant Conservation, Global Trees Campaign, in situ, integrated conservation management, tree conservation

This paper contains supplementary material that can be found online at http://journals.cambridge.org

Nicole Cavender, Murphy Westwood (Corresponding author), Catherine BeChtoldt and Gerard Donnelly The Morton Arboretum, 4100 Illinois Route 53, Lisle, IL 60532, USA. E-mail mwestwood@mortonarb.org

SARA OldFIELD Botanic Gardens Conservation International, Richmond, Surrey, UK

MarTin GaRdner and David RaE Royal Botanic Garden Edinburgh, UK

William McNamara Quarryhill Botanical Garden, Glen Ellen, USA

Received 20 June 2014. Revision requested 28 July 2014.

Accepted 6 October 2014. First published online 9 February 2015.

\section{Introduction}

G lobally, $10 \%$ of all trees $(>8,000$ species $)$ are threaJened with extinction (Oldfield et al., 1998). Although protecting a threatened species in its natural habitat (in situ conservation) is the ideal and most effective way to prevent extinction, there is a growing realization that complementary protection efforts outside a species' natural habitat (ex situ conservation) are also crucial for species' survival (Kramer et al., 2011; Oldfield \& Newton, 2012; Pritchard et al., 2012). The success of in situ conservation is dependent on a variety of factors, including accurate assessment of threats, local community and government engagement, and the susceptibility of native habitat to climate change (Robinson, 2005; Oldfield \& Newton, 2012; Pritchard et al., 2012). Ex situ conservation approaches can complement in situ conservation by strategically avoiding these confounding factors. In some cases a small population size or an imminent threat could render in situ conservation of a tree species unviable, making ex situ conservation the only option to prevent its immediate extinction (McNamara, 2011; Ma et al., 2013). Storage in a seed bank is the most economic and practical way to protect tree species, but many trees, such as oaks, cannot be stored using existing technologies. These 'exceptional' species must be housed in living collections (Pence, 2013). Furthermore, while threatened tree species are growing in living collections, experts can study how they develop, reproduce, and combat disease, and how they might respond to climate change and assisted migration efforts.

The field of ex situ conservation by botanical gardens and arboreta (henceforth referred to as gardens) has been developing since the 1980s (Bramwell et al., 1987; Falk, 1987; Falk \& Holsinger, 1991; Guerrant et al., 2004). Since the first International Botanic Gardens Conservation Congress, in 1985, governments and non-profit organizations have been working to stimulate greater involvement by gardens in plant conservation. Following the 1985 Congress, Botanic Gardens Conservation International was founded to support and coordinate the conservation activities of gardens worldwide. It also promotes and evaluates the progress of national and international conservation policy initiatives, such as the Global Strategy for Plant Conservation, which outlines 16 targets to be achieved by 2020 (CBD, 2012), and the International Agenda for Botanic Gardens in Conservation (BGCI, 2012). 
There are several resources available to guide ex situ conservation efforts, such as the IUCN Red List (IUCN, 2013) and NatureServe threat status listings. There are databases available for searching collections of living plants (e.g. Botanic Gardens Conservation International's PlantSearch, and the Global Biodiversity Information Facility), confirming taxonomic identity (e.g. International Plant Names Index), and exploring distribution maps (e.g. Map of Life). For a review of electronic resources see Lughadha \& Miller (2009). There are several manuals available that outline the practical application of plant conservation by gardens, addressing issues such as collecting germplasm for genetic diversity, developing propagation techniques and implementing reintroduction programmes (Guerrant et al., 2004; Kramer et al., 2011; Maschinski \& Haskins, 2012; BGCI, 2014a; Center for Plant Conservation, 2014).

These resources are useful tools for plant conservation. However, what gardens can do to support conservation of trees, specifically, has been given less attention. Conserving tree species in living collections poses particular challenges, such as accession longevity and space constraints, compared with herbaceous plants. These factors, combined with the problem that long-lived trees adapt more slowly to climate change (Aitken et al., 2008; Gill et al., 2013), make the development of tree-specific conservation resources vital. One such resource is a reference manual produced by Botanic Gardens Conservation International through the Global Trees Campaign (Oldfield \& Newton, 2012), which explains the steps institutions can take to protect threatened tree species, starting with ex situ conservation but also emphasizing in situ conservation, environmental education, public engagement, and reintroduction.

Despite these resources, challenges to ex situ tree conservation still exist and much work is needed to improve the conservation quality of living tree collections in gardens. Many threatened trees are underrepresented in ex situ collections, and genetic breadth is limited (Cibrian-Jaramillo et al., 2013; Cires et al., 2013). The systemic shortfall in ex situ collections is illustrated by assessments of the progress of U.S. gardens towards achieving Target 8 of the Global Strategy for Plant Conservation, which calls for the preservation of $75 \%$ of threatened plant species in ex situ collections, preferably in the country of origin. The USA is less than halfway towards achieving Target 8 and would need to increase the number of new native species protected each year almost tenfold to achieve this target by 2020 (Hird \& Kramer, 2013; BGCI, 2014C). Furthermore, almost 50\% of threatened taxa in the USA are held in just one collection, which represents insufficient genetic diversity to be of conservation value. Although these assessments considered all plant species, not only trees, we know that the outlook is even worse for trees.

There is an urgent need and opportunity for botanical gardens to play a more strategic and active role in supporting global tree conservation through dedicated ex situ tree collections: 'botanic gardens and other ex situ facilities such as seed banks are among the most extensive yet underused plant conservation resources in the world' (Maunder et al., 2004). Gardens have the expertise, facilities and mission to conserve threatened trees, yet few of them are doing it effectively (Maunder et al., 2004; Kramer et al., 2011). Clearly, certain barriers exist to establishing and/or maintaining a high-value ex situ conservation collection of threatened trees.

\section{Objectives and methods}

We employed two strategies to evaluate the current state of ex situ tree conservation. Firstly, we conducted interviews (Supplementary Material 1) with 18 leaders of the botanical garden and conservation communities (see Acknowledgements) to identify barriers to ex situ tree conservation and to explore solutions to the questions posed in the interviews. Secondly, we organized a symposium at the 5th Global Botanic Gardens Congress in New Zealand in October 2013, which included four talks, by WMN, NC, DR and SO. Each presented a case study of how their institutions are contributing to ex situ conservation (summarized in Supplementary Materials 2-5). The presentations were followed by an open discussion, which included many members of the garden community, to promote the exchange of ideas on ex situ tree conservation.

From the interviews and conference symposium there emerged a wealth of information and ideas relating to the current state of ex situ tree collections. Here, we synthesize the opinions, ideas and recommendations of leaders of the global garden community, and formulate strategies to overcome challenges and streamline efforts to make gardens more effective agents for global tree conservation.

\section{Challenges and recommendations}

\section{Evolving the garden mission and collection curation}

Protecting plant species for the purpose of conservation is declared explicitly in the mission statements of most major gardens but few maintain ex situ collections with any real in situ conservation value, especially for tree species. There is often a lack of strategic focus. To evolve their missions, gardens need to develop measurable conservation goals, such as those aligned with the targets and time line of the Global Strategy for Plant Conservation. Furthermore, tree conservation should feature in all aspects of garden operations and activities, including horticulture, education, interpretation, database development and fundraising.

A significant challenge to building high-quality living conservation collections is the historical tradition of regarding living tree collections in the same way as stamp 
TABLE 1 Criteria for prioritizing tree species for ex situ conservation, proposed by Maunder et al. (2004) and experts interviewed for this study.

\begin{tabular}{|c|c|}
\hline Criteria & Rationale \\
\hline $\begin{array}{l}\text { Endangerment (Maunder et al., } \\
\text { 2004) }\end{array}$ & $\begin{array}{l}\text { Arguably the most important consideration. Prioritize tree species based on regional, national \& } \\
\text { international threat lists (e.g. IUCN Red List, NatureServe). }\end{array}$ \\
\hline Endemism (Maunder et al., 2004) & $\begin{array}{l}\text { Tree species with extremely restricted ranges face a high risk of extinction. Protecting threatened } \\
\text { plant species in ex situ collections, preferably in their country of origin, is Target } 8 \text { of the Global } \\
\text { Strategy for Plant Conservation (CBD, 2012). }\end{array}$ \\
\hline $\begin{array}{l}\text { Economically valuable (Maunder } \\
\text { et al., 2004) }\end{array}$ & $\begin{array}{l}\text { Prioritizing tree species that are sources of fibre, medicine, timber or food, or that are crop wild } \\
\text { relatives (e.g. Malus sieversii) contributes to Target } 9 \text { of the Global Strategy for Plant Conservation } \\
\text { (CBD, 2012). }\end{array}$ \\
\hline $\begin{array}{l}\text { Ecologically valuable (Maunder } \\
\text { et al., 2004) }\end{array}$ & $\begin{array}{l}\text { Prioritize keystone tree species that provide significant ecosystem services, such as soil stabilization, } \\
\text { restoring perennial stream flow, cleaning ground water \& supporting biodiversity. }\end{array}$ \\
\hline Emblematic (Maunder et al., 2004) & $\begin{array}{l}\text { Promoting a charismatic, flagship species for conservation purposes is a powerful tool to prevent } \\
\text { extinction (e.g. Sequoia sempervirens, Araucaria araucana, Adansonia spp.). }\end{array}$ \\
\hline Exceptional species & $\begin{array}{l}\text { For living ex situ collections, prioritize tree species with seeds that cannot be viably stored in a seed } \\
\text { bank using current technologies (e.g. Quercus spp.; Pence, 2013). }\end{array}$ \\
\hline Expert opinion & $\begin{array}{l}\text { Formal threat assessments such as the IUCN Red List require extensive \& time-consuming data } \\
\text { gathering \& can take months, even years, to publish. When conservation measures are needed } \\
\text { urgently, knowledgeable tree experts should push for action, \& gardens should consult these experts } \\
\text { to gather the necessary information to prioritize immediate conservation action. }\end{array}$ \\
\hline Evolutionary significance & $\begin{array}{l}\text { Species from monotypic genera or sparsely populated phylogenetic lineages represent valuable } \\
\text { genetic diversity that should be protected (e.g. Wollemia nobilis, Ginkgo biloba). }\end{array}$ \\
\hline
\end{tabular}

collections, where curators focus on acquiring one individual of many species. Such synoptic collections have limited use in conservation because they represent a relatively small gene pool. The most important consideration when assessing the conservation value of an ex situ collection is to maximize the depth and breadth of its genetic diversity, relative to wild populations, across the entire geographical range of the species ( $\mathrm{Li}$ et al., 2005; Namoff et al., 2010; Samain \& Cires, 2012; Cibrian-Jaramillo et al., 2013; BGCI, 2014a).

Curating a high-quality living conservation collection of trees is a challenging undertaking that requires a long-term management strategy to maintain genetic diversity and prevent hybridization, genetic drift and artificial selection from degrading its value. There is a trade-off between the number of tree species a garden can maintain in collections and the depth of each collection. Because of diminishing marginal returns there is an ideal size at which a collection preserves the most genetic diversity at the least cost. This size depends on the species' life history, generation time, breeding system and population dynamics. Pioneering studies have been conducted for a few plant species, to predict the optimal size for a conservation collection, but more research is needed to develop scientifically informed models for a phylogenetic range of tree taxa (Griffith \& Husby, 2010; Griffith et al., 2011; Cibrian-Jaramillo et al., 2013; BGCI, 2014a).

The ultimate goal for a garden should be a well-curated ex situ conservation collection of multiple accessions that represents the genetic diversity of wild populations, with collaborative in situ initiatives for reintroduction and habitat protection, leading to recovered wild populations of healthy trees: an integrated conservation management strategy (Falk,
1987; Oldfield \& Newton, 2012). One example is the Acerpentaphyllum conservation programme at Quarryhill Botanical Garden, Glen Ellen, USA. The last remaining wild population of this Critically Endangered Chinese endemic tree is under imminent threat by dam construction. Quarryhill has established a conservation grove of 200 wild-origin trees, and research is underway to improve cultivation methods. The garden is also working with local communities in China to promote in situ conservation of the species (Supplementary Material 2).

\section{Prioritizing tree species for conservation}

How to prioritize tree species for conservation was the most controversial topic amongst the experts interviewed. The reality is that no single garden can protect all of the $>8,000$ threatened tree species. Many gardens may only have sufficient resources to invest in the conservation of a few or only one target species, but that in itself would be progress. Maunder et al. (2004) described five factors to consider when making decisions about which tree species to prioritize for ex situ conservation; here we add three more (Table 1).

Most importantly, gardens should be pragmatic and realistic in scope, and assess their own circumstances when prioritizing species for conservation. Available resources and space, the existing collection, local scientific expertise, regional habitat and climate (and predicted future climate), and the interests of the local community are all important variables to consider. Species must be chosen that complement these needs and conditions, for ease of 
implementation and to maximize the success of the conservation collection.

\section{Information technology and data management}

With the rise of the big-data era the gap in basic biological information and database management technology for tree conservation purposes is obvious. There is a lack of critical biological and ecological information at the species level for the majority of trees. In a 1998 Red List assessment of trees (Oldfield et al., 1998) there were sufficient data available to evaluate c. 10,000 species, just $10 \%$ of the predicted total of 100,000 species. Gaps in knowledge about tree taxonomy and phylogeny, reproductive ecology, seed biology (specifically whether a species may be considered exceptional), and species distributions limit the ability of gardens to prioritize tree species for maximum conservation impact.

There are many strategies that gardens can employ, both individually and as a coordinated community, to address these information gaps. Gardens can work with academia to improve scientific rigour in tree research. The dissemination of research and conservation results (both successes and failures) is of utmost importance to enhance collective knowledge and prevent unnecessary duplication of effort. New communication channels such as social media networks can be fast and efficient ways of sharing information. It is important for gardens to promote botanical degree programmes, teach courses and mentor students, to ensure that the next generation of plant scientists, horticulturalists and collections curators is prepared to take over. Another strategy for generating knowledge is to create collaborative hubs of tree science research, linking the garden community with other sectors. Forming these broad institutional alliances promotes the exchange of technology, improves access to conservation facilities (e.g. genetic analysis laboratories, seed banks and tissue culture laboratories), and leverages strengths and resources from different institutions to increase funding opportunities. The Center for Tree Science at The Morton Arboretum is an example of this strategy. It brings together experts from gardens, academia, industry, government and non-profit organizations to catalyse innovative research, provide new training opportunities, and develop solutions to the challenges facing trees in urban areas and in the wild (Supplementary Material 3).

A well-managed database is critical to a collection's conservation value but this is an area where technology, data sharing, and process standardization are limited. Botanic Garden Conservation International's PlantSearch database (BGCI, 2014b) facilitates gardens to make their collection records openly accessible but participation is voluntary and requires regular updating. Not all of the contributed data are made publicly available because of concerns over the security of threatened species. Sharing collections data, especially genetic diversity information, is key to facilitating collaborations and understanding which tree species are receiving ex situ conservation attention. Collections databases also provide valuable information on species distributions. Gardens can improve the conservation quality of their collections by contributing occurrence data (for both living and herbarium collections) to open-access databases such as the Global Biodiversity Information Facility (GBIF, 2014) and iDigBio (iDigBio, 2011), which enable meta-analysis of biodiversity data, encourage standardization of collections data, and improve understanding of the distribution of tree species (e.g. Pimm et al., 2014). This is one area where citizen science initiatives can make a significant impact, for example by crowd-sourcing the collation of information from digitized herbarium sheets into databases.

\section{Working together at a global scale}

There is limited regional or international coordination of tree conservation efforts within the global community of $>3,200$ botanical gardens and arboreta. Although gardens have a long tradition of reciprocal plant exchange and joint collecting expeditions, collaborative conservation programmes are still uncommon. Communication among distant gardens is becoming easier through social media but this network is ad hoc and unorganized. National professional organizations (e.g. the American Public Garden Association) and networks (e.g. the Center for Plant Conservation) are good catalysts and models to promote cross-institutional collaborations for tree conservation but are limited in geographical scope. There is potential to build a stronger, coordinated, global network, which is essential to confront the global tree diversity crisis.

Gardens can collaborate more effectively by participating in international tree-focused networks such as the Global Trees Campaign and ArbNet. The Global Trees Campaign, a joint initiative of Fauna \& Flora International and Botanic Gardens Conservation International, has $>20$ years' success in tree conservation, reforestation projects, red-listing initiatives and environmental education programmes, and providing tree conservation resources. The most significant asset of the Global Trees Campaign is its ability to promote cross-institutional collaborations and connect tree-focused gardens with in situ conservation opportunities. ArbNet is another global networking organization that fosters professionalism, provides guides and resources, and promotes conservation collaborations among arboreta (Supplementary Material 3).

Gardens can work more collaboratively by establishing or joining a hub of conservation action, in which one organization or consortium takes responsibility for coordinating 
the conservation activities for a particular taxonomic group or geographical region. These activities can include maintaining living collections (e.g. North American Plant Collections Consortium), monitoring and restoring wild populations (e.g. Center for Plant Conservation, Ecological Restoration Alliance) and coordinating redlisting efforts (e.g. Global Trees Campaign). The International Conifer Conservation Programme, based at the Royal Botanic Garden Edinburgh, is a conservation consortium that conducts field surveys, threat assessments and propagation research for conifers, $34 \%$ of which are threatened (IUCN, 2013). It also operates an innovative programme of safe sites for genetically diverse ex situ conservation collections of threatened conifers. These sites include $>200$ public parks, private estates, golf courses, hotels, monasteries and hospitals that are growing thousands of threatened conifers. This model facilitates the participation of non-traditional gardens in tree conservation and provides an exponential increase in the number of threatened trees protected, outsourcing of custodial care for ex situ collections, and a wider choice of growing sites (Supplementary Material 4).

Another way to broaden the impact of the global network is to empower smaller gardens (e.g. college arboreta, public parks, cemeteries, private tree collections) to contribute to ex situ tree conservation. These gardens can collaborate with leading gardens by volunteering to grow threatened tree species, similar to the International Conifer Conservation Programme's safe site approach. This is especially valuable when smaller gardens are located in ecologically unique, valuable or threatened habitats. Smaller gardens can leverage the expertise, resources and germplasm available from larger gardens to support tree conservation efforts, and can also act as local liaisons to facilitate collecting trips, monitor local threatened tree populations and support citizen science programmes. Land owners of all types, such as municipalities, universities, religious organizations, golf courses, cemeteries and private estates, could be recruited to conserve threatened trees on their property through a coordinated approach led by larger gardens or conservation consortia.

In addition to empowering smaller gardens it is particularly important for the global garden community to build capacity and lobby for in situ tree conservation in biodiversity hotspots, where there is generally less access to resources and training opportunities. This is accomplished through institutional partnering and international conservation collaborations. One example is the collaboration between the Global Trees Campaign and Brackenhurst Botanic Garden in Kenya. Established in 2001, Brackenhurst Botanic Garden was created by replanting a clear-cut valley with native trees of East African tropical submontane forest. Several native tree conservation initiatives have been implemented there, including propagation programmes, botanical tours, ecology education programmes and a native seed collecting collaboration with the Millennium Seed Bank Project (Supplementary Material 5). The Global Trees Campaign, Kew Gardens and Missouri Botanical Garden support Brackenhurst by raising global awareness of the programme, providing training and advisory support, garnering additional funding, and managing funds generated in the USA so that donations are exempt from taxation. When leading gardens support tree conservation at gardens in biodiversity hotspots they have a significant impact because of the urgent need for action, the lack of local aid, and the higher relative purchasing power of funds in these regions.

Exchanging plant material is another important way the global garden network can improve tree conservation efforts. Gardens can expand the genetic breadth and thus increase the conservation value of their tree collections in a cost-effective manner by sourcing well-documented, wild-origin accessions from other gardens. National and international conservation policies, such as CITES and the Convention on Biological Diversity, can be both a help and a hindrance to international exchange of plants. These conventions are beneficial because they contribute to global biodiversity conservation, guide governments to enact environmental policy, and regulate international access and benefit sharing. However, inconsistent implementation by some countries has impeded scientific collecting efforts by experts with legitimate research and conservation goals (Roberts \& Solow, 2008). This is a complex and delicate diplomatic situation to resolve but there are two complementary solutions. In the long term the most sustainable solution is to build capacity at gardens in biodiversity hotspots so they can maintain 'near situ' conservation collections of threatened endemic trees. In the short term the garden community can advocate for urgently needed ex situ conservation collections, and encourage the Parties to CITES and the Convention on Biological Diversity to consider an exemption for nonprofit gardens to export threatened tree species strictly for conservation and research purposes. Table 2 presents a summary of the key conservation recommendations.

\section{Conclusions}

Botanical gardens and arboreta represent the accumulated knowledge of hundreds of years of plant identification, taxonomy, collecting, horticulture and curation. They also have the land and facilities, such as breeding nurseries, tissue culture laboratories and seed banks, required to maintain genetically diverse tree collections in the long term. With these strengths and assets, gardens are in a unique position to play a significant role in mitigating the global tree biodiversity crisis through ex situ conservation. 
TABLE 2 Practical recommendations for botanical gardens and arboreta to improve conservation efforts and increase the value of ex situ tree collections.

Recommendation Details

\section{Evolve the garden mission \& curation of collections}

Focus garden mission

Ensure that tree conservation is an explicitly stated component of the institutional mission. Align the institutional strategic plan, including well-developed \& measurable conservation goals, with the targets \& timeline of the Global Strategy for Plant Conservation.

Make conservation a focus not only of living collections but also of databases, propagation strategies, education, interpretation \& fundraising efforts.

Manage collections for conservation value

Advance the collection mentality from one of 'stamp collecting' to collecting for conservation purposes (i.e. many wild-collected, well-curated, genetically diverse individuals).

Think beyond the collection towards an integrated conservation management strategy that includes reintroduction \& in situ habitat protection, leading to recovery of healthy tree populations.

Develop seed bank collections when viable.

Prioritize threatened exceptional tree species (i.e. those that cannot be stored in a seed bank using conventional methods) for living conservation collections. Be pragmatic \& realistic in scope when developing conservation collection priorities.

Replicate conservation collections (i.e. share accessions) across institutions as an insurance policy against natural disasters, disease \& institutional closures.

To ensure the long-term preservation of genetic diversity of ex situ conservation collections, propagate genetically valuable accessions, maintain an optimized age distribution \& administer a strategic breeding programme.

Maintain detailed records of living collections \& share collections data through open-access databases.

Collect for tree conservation

When designing collecting strategies, maximize the number of wild-collected accessions \& maternal lines from across the range of the species.

Collect threatened trees opportunistically, keeping in mind the population genetic factors that influence collection quality.

Ensure rigorous provenance documentation for every accession at the time of collection.

\section{Improve coordination between gardens}

Use existing networks

Establish new relationships

Improve communication

Use established models
Champion Botanic Gardens Conservation International, the Global Trees Campaign \& ArbNet as mechanisms for unifying the garden community \& building the global network. Establish or join a hub of conservation action, in which one organization or consortium takes responsibility for coordinating the conservation activities of a particular taxonomic group or geographical region.

Lobby the Parties to CITES \& the Convention on Biological Diversity to consider an exemption for non-profit gardens to export threatened tree species strictly for conservation \& research purposes.

Initiate collaborations with gardens locally \& globally to streamline conservation efforts, share ideas \& resources, \& exchange threatened plant material.

Embrace opportunities to recognize \& acknowledge colleagues \& publicize collaborative efforts.

Join the conservation conversation by participating in a variety of communication channels, including social media, attending conferences \& subscribing to professional organizations.

Learn from other organizational models, such as the American Zoological Association \& the National Institutes of Health, both of which have an explicit, unified purpose \& manage centralized, well-organized, open-access databases of biological information.

\section{Empower smaller gardens to conserve trees}

What any garden can do

Prioritize seed sourced from wild populations \& ensure thorough documentation of collections.

Collaborate with leading gardens by volunteering land to grow threatened tree species (especially valuable when smaller gardens are in ecologically unique, valuable or threatened habitats).

Leverage the expertise, resources \& germplasm already available from leading gardens to support tree conservation programmes.

Emphasize conservation to the public through education \& interpretation.

Act as local liaisons to facilitate collecting trips, monitor local threatened tree populations \& support citizen science programmes. 
Table 2 (Cont.)

\begin{tabular}{ll} 
Recommendation & Details \\
\hline How leading gardens can help & Develop complementary tree conservation programmes with smaller or less well-resourced \\
gardens. & Coordinate \& facilitate conservation between many different institutions to streamline efforts. \\
& Recruit \& support land owners of all types (e.g. city councils, universities, religious organizations, \\
& golf courses, cemeteries, private estates) to participate in tree conservation on their property. \\
& Build capacity for gardens in biodiversity hotspots through institutional partnering \& \\
& developing models of conservation action that other gardens can adopt. \\
& Lobby for in situ conservation initiatives \& habitat protection in areas of high biodiversity but \\
& that have low capacity for protecting threatened trees.
\end{tabular}

\section{Advance information technology \& close gaps in knowledge}

Collaborate \& share information

Strengthen ties with academia to enhance scientific rigour in tree research, improve access to scientific facilities \& increase cross-disciplinary funding opportunities.

Participate in researcher exchanges between institutions to share knowledge.

Publicize research \& conservation project results (both successes \& failures) in traditional (e.g. peer-reviewed journals, conference proceedings) \& non-traditional (e.g. social media, blogs, popular science articles, newsletters, podcasts) media channels.

Prioritize conservation-focused tree Include funds for comparative genetic analysis of ex situ \& in situ tree populations when science research applying for grant funding.

Study living collections of threatened species to improve understanding of basic biology, reproduction, growth \& disease resistance.

Increase research on seed banks, cryopreservation, tissue culture, \& micropropagation techniques for exceptional tree species, to improve efficiency \& cost-effectiveness.

Increase research on tree biology, taxonomy, phylogeny \& reproductive ecology.

Develop horticultural \& propagation protocols for exceptional species.

Create tree-specific conservation models \& guidelines
Develop scientifically informed models, based on specific life history traits, reproductive biology \& distribution, for a range of tree taxa to predict the minimum necessary size for an ex situ living collection for conservation purposes.

Develop standard protocols for maintaining \& curating ex situ conservation collections of trees.

Develop an industry-wide process for sharing collections information, including living trees, herbarium specimen data \& genetic diversity data.

Contribute to conservation databases
Coordinate or contribute to efforts to evaluate extinction risk of tree species through the IUCN Red List assessment process.

Employ best practices in database management \& georeferencing (see guidelines at iDigBio, 2011).

Share living collections \& herbarium data with databases such as PlantSearch \& the Global Biodiversity Information Facility.

\section{Promote conservation-focused education, training \& public engagement}

Create training opportunities

Interpret \& educate

Involve the community
Train others in all aspects of tree science \& care, especially students, \& local people in biodiversity hotspots with threatened in situ tree populations.

Promote botanical undergraduate \& graduate programmes, ensuring the next generation of plant scientists, horticulturalists \& collections curators is prepared.

Support training programmes by mentoring students \& interns.

Use living tree collections to create conservation-focused interpretation displays that are informative, engaging \& innovative, \& that inspire a call to action.

Empower \& educate the public on how they can contribute to tree conservation efforts, for example by choosing native or threatened woody species in their home landscaping. Incorporate conservation-focused fundraising opportunities into garden interpretation \& public events (e.g. offer an adopt-a-tree programme for threatened species or highlight an ongoing in situ tree conservation programme to which the public can donate).

Leverage existing outreach channels, such as public education programmes, summer camps \& special events, to communicate the importance of tree conservation to the general public. Develop citizen science programmes to engage the public in tree conservation \& help generate valuable biodiversity data (e.g. collating information from digitized herbarium sheets, or documenting rare species sightings using specialized smartphone applications).

Realize that prioritizing conservation is actually an asset, not an expense, which helps attract visitors \& revenue streams to botanical gardens \& arboreta. 
A number of challenges to effective ex situ tree conservation need to be confronted, however, including a lack of strategic conservation focus, collection management limitations and gaps in fundamental biological information for trees. Some of these challenges are more difficult to solve than others. The dearth of basic information on many tree species and of sharing and management of biological data will require significant effort to overcome. Gardens must unite as a global community to identify the most critical knowledge gaps, coordinate research efforts and share data and results openly. Working with academia and experts from other sectors and establishing collaborative hubs of research and conservation will promote innovative thinking and technological solutions to overcome these problems. Such multidisciplinary collaborations can garner more funding from traditional sources and unlock new funding opportunities from nontraditional sources, such as private corporations and the impact investment market.

An easier limitation to overcome is evolving the collection mentality to be more conservation focused. An important step is prioritizing well-curated, genetically diverse collections of many wild-origin accessions to maximize reintroduction potential. Gardens of all sizes have multiple purposes but more gardens could evolve their missions to include conservation as a core value. There are already frameworks in place (e.g. the Global Strategy for Plant Conservation, the International Agenda for Botanic Gardens in Conservation) that articulate goals, define time lines and guide conservation actions for the international garden community.

Many of the recommendations described here can be implemented by individual gardens but some challenges can only be overcome by gardens working together more effectively. To improve the impact of this global network it is important to empower smaller gardens to participate in conservation action, and to build capacity in gardens in biodiversity hotspots. Networks such as the Global Trees Campaign and ArbNet are already in place to support conservation collaborations within the global garden community and provide a single voice to represent gardens in conservation advocacy. Models of innovative ex situ tree conservation exist for gardens to emulate. Even by taking small steps, such as focusing efforts on one threatened tree species or using living collections to educate the public about global tree conservation issues, gardens of all sizes can contribute significantly to conservation efforts. Because the threats to tree species diversity are complex and global, a coordinated effort is needed to fill knowledge gaps, share information and build global capacity to protect tree species from extinction.

\section{Acknowledgements}

We thank everyone who participated in the insightful discussions and interviews, including but not limited to
Matthew Albrecht, Pam Allenstein, Kris Bachtell, Dan Beetem, Michael Dosmann, Patrick Griffith, Kunso Kim, Andrea Kramer, Daniel Luscombe, Mark Nicholson, Peter Raven, Mark Richardson, Nigel Taylor, Elango Velautham and Sun Weibang.

\section{References}

Aitken, S.N., Yeaman, S., Holliday, J.A., Wang, T. \& Curtis-McLane, S. (2008) Adaptation, migration or extirpation: climate change outcomes for tree populations. Evolutionary Applications, 1, 95-111.

BGCI (Botanic Gardens Conservation International) (2012) International Agenda for Botanic Gardens in Conservation. 2nd edition. Botanic Gardens Conservation International, Richmond, UK.

BGCI (2014a) Building Living Plant Collections to Support Conservation: A Guide for Public Gardens. Botanic Gardens Conservation International, Richmond, UK.

BGCI (2014b) PlantSearch. Http://www.bgci.org/plant_search.php [accessed 25 November 2014].

BGCI (2014c) Progress Report on Target 8 of the Global Strategy for Plant Conservation in the United States. Botanic Gardens

Conservation International, Richmond, UK.

Bramwell, D., Hamann, O., Heywood, V. \& Synge, H. (eds) (1987) Botanic Gardens and the World Conservation Strategy. Academic Press, Ann Arbor, USA.

CBD (Convention on Biological Diversity) (2012) Global Strategy for Plant Conservation 2011-2020. Botanic Gardens Conservation International, Richmond, UK.

Center for Plant Conservation (2014) Bibliographies. Http:// www.centerforplantconservation.org/Bibliographies.asp [accessed 25 November 2014].

Cibrian-Jaramillo, A., Hird, A., Oleas, N., Ma, H., Meerow, A.W., Francisco-Ortega, J. \& Griffith, M.P. (2013) What is the conservation value of a plant in a botanic garden? Using indicators to improve management of ex situ collections. The Botanical Review, 79, 559-577.

Cires, E., De Smet, Y., Cuesta, C., Goetghebeur, P., Sharrock, S., Gibis, D. et al. (2013) Gap analyses to support ex situ conservation of genetic diversity in Magnolia, a flagship group. Biodiversity \& Conservation, 22, 567-590.

FALK, D. (1987) Integrated conservation strategies for endangered plants. Natural Areas Journal, 7, 118-123.

Falk, D. \& Holsinger, K. (eds) (1991) Genetics and Conservation of Rare Plants. Oxford University Press, Oxford, UK.

GBIF (Global Biodiversity Information Facility) (2014) Http://www.gbif.org/ [accessed 25 November 2014].

Gill, D., Magin, G. \& Bertram, E. (2013) Trees and Climate Change. Fauna \& Flora International, Cambridge, UK.

Griffith, P. \& Husby, C. (2010) The price of conservation: measuring the mission and its cost. BGJournal, 7, 12-14.

Griffith, P., Lewis, C. \& Francisco-Ortega, J. (2011) Palm conservation at a botanic garden: a case study of the Keys Thatch Palm. Palms, 55, 93-101.

Guerrant, Jr, E.O., Havens, K. \& Maunder, M. (eds) (2004) Ex Situ Plant Conservation: Supporting Species Survival in the Wild. Island Press, Washington, DC, USA.

Hird, A. \& Kramer, A.T. (2013) Achieving Target 8 of the Global Strategy for Plant Conservation: lessons learned from the North American Collections Assessment. Annals of the Missouri Botanical Garden, 99, 161-166. 
iDigBio (Integrated Digitized Biocollections) (2011) Https:// www.idigbio.org/ [accessed 25 November 2014].

IUCN (2013) IUCN Red List of Threatened Species v. 2013.2. Http:// www.iucnredlist.org [accessed 1 February 2014].

Kramer, A., Hird, A., Shaw, K., Dosmann, M. \& Mims, R. (2011) Conserving North America's Threatened Plants: Progress Report on Target 8 of the Global Strategy for Plant Conservation. Botanic Gardens Conservation International U.S. Glencoe, USA.

Li, Y., Chen, X., Zhang, X., Tian-Yi, W., Hui-Ping, L. \& Yue-Wei, C. (2005) Genetic differences between wild and artificial populations of Metasequoia glyptostroboides: implications for species recovery. Conservation Biology, 19, 224-231.

Lughadha, E. \& Miller, C. (2009) Accelerating global access to plant diversity information. Trends in Plant Science, 14, $622-628$.

Ma, Y., Chen, G., Grumbine, R.E., Dao, Z., Sun, W. \& Guo, H. (2013) Conserving plant species with extremely small populations (PSESP) in China. Biodiversity \& Conservation, 22, 803-809.

Maschinski, J. \& Haskins, K.E. (eds) (2012) Plant Reintroduction in a Changing Climate. Promises and Perils. Island Press, Washington, DC, USA.

Maunder, M., Guerrant, Jr, E.O., Havens, K. \& Dixon, K. (2004) Realizing the full potential of ex situ contributions to global plant conservation. In Ex Situ Plant Conservation: Supporting Species Survivial in the Wild (eds E.O. Guerrant Jr, K. Havens \& M. Maunder). Island Press, Washington, DC, USA.

McNamara, W.A. (2011) 708. Acer pentaphyllum. Curtis's Botanical Magazine, 28, 128-140.

Namoff, S., Husby, C.E., Francisco-Ortega, J., Noblick, L.R., Lewis, C.E. \& Griffith, M.P. (2010) How well does a botanical garden collection of a rare palm capture the genetic variation in a wild population? Biological Conservation, 143, 1110-1117.

Oldfield, S., Lusty, C. \& MacKinven, A. (1998) The World List of Threatened Trees. World Conservation Press, WCMC, Cambridge, UK.

Oldfield, S. \& Newton, A. (2012) Integrated Conservation of Tree Species by Botanic Gardens: A Reference Manual. Botanic Gardens Conservation International, Richmond, UK.
PENCE, V.C. (2013) In vitro methods and the challenge of exceptional species for Target 8 of the Global Strategy for Plant Conservation. Annals of the Missouri Botanical Garden, 99, 214-220.

Pimm, S.L., Jenkins, C.N., Abell, R., Brooks, T.M., Gittleman, J.L., Joppa, L.N. et al. (2014) The biodiversity of species and their rates of extinction, distribution, and protection. Science, 344, 1246752.

Pritchard, D.J., Fa, J.E., Oldfield, S. \& Harrop, S.R. (2012) Bring the captive closer to the wild: redefining the role of ex situ conservation. Oryx, 46, 18-23.

Roberts, D.L. \& Solow, A.R. (2008) The effect of the Convention on International Trade in Endangered Species on scientific collections. Proceedings of the Royal Society B, 275, 987-989.

Robinson, D. (2005) Assessing and addressing threats in restoration programmes. In Forest Restoration in Landscapes: Beyond Planting Trees (eds S. Mansourian, D. Vallauri \& N. Dudley), pp. 73-77. Springer, New York, USA.

SAmain, M. \& Cires, E. (2012) Plants for the future-a future for our planet: towards a protocol for genetic management of ex situ living plant collections. BGJournal, 9, 3 .

\section{Biographical sketches}

Nicole Cavender's research interests include ecological restoration, disturbance ecology and conservation biology. MURPH Y WESTW OOD's interests include ex situ conservation of globally threatened tree species, conservation genetics, and angiosperm evolution. CATHERINE BECHTOLDT's research interests include wildlife ecology and species distributions. Gerard Donnelly's background is forest ecology and he leads The Morton Arboretum's focus on tree conservation and international collaboration. SARA OLDFIELD's primary research interests are integrated conservation management of threatened tree species and facilitating tree threat assessments. MARTIN GARDNER specializes in conifer species distributions, conservation genetics, and ex situ collections. DAVID RAE's research interests include developing horticultural techniques and living plant collections for conservation purposes. BiLl McNAm A R s specializes in the flora of East Asia, focusing on threatened species and ex situ conservation collections. 